\title{
THE CORRELATION BETWEEN ASSESSMENT FOR LEARNING AND CONSTRUCTIVE ALIGNMENT BASED ON AGE
}

\author{
${ }^{1}$ Erwin Akib, ${ }^{2}$ Arie Martuty, ${ }^{3}$ Mohd. Najib bin Abdul Ghaffar, ${ }^{4}$ Jamilah binti Ahmad \\ ${ }^{1,2}$ FKIP Universitas Muhammadiyah Makassar \\ ${ }^{3,4}$ Fakulti Pendidikan Universiti Teknologi Malaysia
}

\begin{abstract}
The assessment practice in Indonesian Higher Education presently uses the traditional methods, which are assessment for learning and assessment as learning. However, the new perspective on assessment proposes that it should include the process of learning called Assessment for Learning (AFL) and this assessment can be enhanced through the Constructive Alignment (CA) method. The main objective of this study was to determine the correlation between AFL and CA based on age. The respondents of this study were 454 lecturers of 11 Universities selected through multistage cluster sampling method. This study used explanatory sequential design, a combination of quantitative and qualitative method. Quantitative data were obtained using questionnaires followed by qualitative data collection using interviews. The qualitative data were used to explain the quantitative data results. Quantitative data were analyzed using ANOVA, chi-square, and SEM. The validity and reliability of the instruments were determined using the Rasch Model. The findings showed that there was a high correlation level of AFL and CA practice among the lecturers.
\end{abstract}

Keywords: Assessment for Learning, Constructive Alignment, Indonesian Higher Education

\section{INTRODUCTION}

The assessment is to produce information to know ahead of the next study (Berry and Adamson, 2011; Carless, 2007; Hogan and Gopinathan, 2008). Currently, the evaluation system in some regions has changed. Assessment as Learning (AAL) and Assessment for Learning (AFL) were two new concepts in the assessment. AAL and AFL were form the basis for assessment reform in the system of primary education in the Asia-Pacific region, including Indonesia (Mok, 2012).

Furthermore, assessment in Hong Kong, Korea, China, Japan, Macau, Singapore and Taiwan, for example, traditionally in the form of high-stake norm-referenced examinations that defined the future prospects of education and employment test participants (Berry and Adamson, 2011; Hogan and Gopinathan, 2008; Mok, 2012). Evaluation system used in Indonesia based on the national curriculum that included assessment procedures at all levels of education. However, Indonesia had embraced for the assessment of learning. Assessment associated with behaviourist views of learning aims to check whether the learners have encountered the requirements as set. A Judgment will be made by compare the predetermined learning targets and the ultimate performance of the learner. This view of assessment places a major focus on the product of learning. This kind of assessment represents Assessment of Learning (Berry, 2008).

Assessment for learning comes from two main words, the assessment and learning. Definition of assessment for learning has been widely expressed by experts, such as; Assessment for learning is part of everyday practice by students, teachers and peers that seeks, reflects upon and responds to information from dialogue, demonstration and observation in ways that enhance ongoing learning (Klenowski, 2009). This meaning was making to emphasize the progress of learning. The lifelong learning skills as goal assessment for learning and recognizes the importance of both the right workout and casual laid in teaching and learning every day.

Assessment for Learning (AFL) is the process of seeking and interpreting evidence for use by learners and their teachers to decide where the learners are in their learning, where they need to go and how best to get there. (Assessment Reform Group, 2002). AFL involves teachers providing descriptive rather than evaluative feedback and students' self-assessing and communicating their 
own result to others (Stiggins, Arter, Chappius \& Chappius, 2006).

Historically, the term of assessment for learning began with the term formative assessment. That included an assessment for learning, and had been detected by Black \& Wiliam (2006) and Newton (2007) from Scriven (1967) first writing that distinguished between formative and summative assessment purposes, the work of Bloom, Hasting and Madaus (1971) and the work of Sadler (1989), which highlights the importance of formative set criteria to inform students about learning.

Finally, Sambell K, McDowell L, and Montgomery C (2013), emphasized that Assessment for Learning is an integrated approach to teaching assessment and supporting student learning. Furthermore, it presents a manifesto built on the overall ethos Assessment for Learning as an integrated whole and addresses the key foundations of Assessment for Learning. The key foundations of AFL can be used to guide reflection on current practice and lead to an emerging agenda which requires transformed roles, relationships, sense of responsibilities and new ways of thinking that are needed to bring a culture of AFL about.

Constructive alignment is an important principle in devising teaching and learning activities such as lectures tutorial classes and assessment so that both teachers and learners focus on the outcomes of the context (Biggs, 1996). The instructional design is vital to relate curriculum and learning outcomes. The launch of CA as a new way of designing courses is partly a consequence of the fact that universities and colleges have become mass-education institutions (Biggs and Tang, 1999; 2007).

The principles of constructive alignment (Biggs 1996; Biggs 1999; Biggs and Tang 2007) had long promoted as a powerful approach to facilitating improved student outcomes for a broader range of students. Despite some concern in the science education sector that constructivist approaches undermine the mastery of disciplinary knowledge and independent thinking (Jervis and Jervis 2005), there has been considerable attention in recent years to the concepts of constructive alignment (Boud and Falchikov 2006) and a general view as to its benefits (Rust 2002). However, there remains little evidence of its systematic implementation and even less evidence of its evaluation, particularly from a student perspective.

Curriculum, instruction, and assessment are the three central tenets of education that aim to develop students' abilities to think, solve problems, and become independent learners (Pellegrino, 2002). Instruction is comprised of the methods of teaching and the learning activities engaged in by professors and students in order to achieve the objectives, which guided by the curriculum.

The construction of this knowledge is therefore based not only on the types of teaching and learning activities, but on what a student brings to the learning environment, such as prior knowledge, experience, attitudes, and on assumptions (Biggs, 2003). Furthermore, Biggs (1996) talks about the merging of constructivism and instructional design when he identifies the alignment of three components: (a) measurable, clearly-stated, curriculum or unit objectives, (b) learning activities that will help students gain and understand content knowledge, and (c) assessment tasks that utilize new knowledge to meet stated objectives (Biggs, 1999; Biggs, 2003, Harvey and Kamvounias, 2008).

Constructive alignment is a principle that is used to develop teaching and learning activities, and assessment tasks, so that they directly address the learning outcomes (Biggs \& Tang, 2007). A literature review on the learning outcomes has the same meaning. Some experts say, as follows: The learning outcomes are statements of what students expected to be able to do as a product of learning activities (Jenkins and Unwin, 2001). Although Bingham (1999) states that learning outcomes are clear descriptions of what students should know, understand and be able to do as a result of learning.

The alignment of assessment tasks to learning outcomes, as described Biggs and Tang (2007), reinforced by others. Brown (20042005) proposes that assessment tasks need to be authentic and fit for the purpose of the desired learning outcomes. The link between what students expect to learn and how they are required to demonstrate this learning needs to be clear. Thus, teaching staff needs to use a variety of assessment strategies and tasks that relate directly to the range of intended learning outcomes (Rust 2002), and the verbs that used within the 
learning outcomes. The focus is therefore, not the assessment of learning but assessment for learning. Brown argues that assessment tasks should not be a bolt-on component of curriculum development, but instead need to be aligned with intended learning outcomes as described by Biggs and Tang (2007).

\section{RESEARCH METHODOLOGY}

This research design as an explanatory sequential mixed method provides a better practice of the relationship between Assessment for Learning and Constructive Alignment. Creswell (2012) defined the explanatory sequential mixed method as a method that involves the procedure of first gathering quantitative data to explore a phenomenon, and then collecting qualitative data to explain relationship found in qualitative data. Its central premise is the use of quantitative and qualitative approaches in combination provides a better understanding of research problems than either approach understanding of research problems than either approach alone (Creswell, 2012; Creswell, 2009; Creswell, 2002).

This research emphasized primarily on confirmatory scientific method, because it was concentrated on hypothesis testing and theory testing. Investigators in quantitative research were tending to stand on one's hypothesis and then examine and test those hypotheses with empirical data whether there were relationships among the variables (Creswell, 2009) This study also explored individuals' or groups' meaning in human problem, used to describe what was seen locally and come up with new hypotheses. The merger and combination of those two approaches above generated a mixed-method research approach. (Johnson \& Onwuegbuzie, 2004). This study assumed that cognition and behavior were highly predictable and explainable, which meant that all events were fully determined by one or more causes. The researcher also viewed human behavior as being fluid, dynamic, and changing over time and place. Thus, qualitative data would also be collected to compliment the quantitative data.

This research conducted a mixed method design. It was conducted since the study investigated teachers' epistemological belief, teachers' preferred test, and the relationship between them quantitatively, and proposing a framework of preferred test based on teachers' epistemological belief qualitatively. Since there so many types for classifying and identifying types of mixed methods strategies, the researcher needed to mention those types of mixed method to get a better understanding about this type of mixed method. Particularly, quantitative methods were used through questionnaires and qualitative methods were using the interviews.

The main purpose of this study was to determine the relationship between assessment for learning and constructive alignment in teaching learning process at the university. This research was a mixed method which was a combination of methods to harness the power of quantitative and qualitative research methods at once. Before applying mixed methods, researchers need to identify the strategy of mixed methods as procedures in collecting, analyzing and reporting data. Therefore, strategy used in this research was sequential explanatory, where this research begins with a quantitative process, and then the process was qualitative. The sequential explanatory strategy in mixed methods research was characterized by the collection analysis of quantitative data in first phase followed by the collection and analysis qualitative data in a second phase that build on the result of initial quantitative results, Creswell (2009).

The explanatory sequential design was completed in two stages, namely quantitative research conducted through the first stage using a questionnaire and then followed by a second phase with a qualitative study using interviews and document (Creswell and Clark, 2007). Quantitative data were collected and analyzed first and then the qualitative data. Qualitative data used to support or elaborate explanations quantitative data results. The process of merging the data in this method occurs when the initial results of the quantitative inform qualitative data collection. Therefore, both quantitative and qualitative data are separated but stay in touch (Creswell and Clark, 2007). The methods used in quantitative was survey by using a questionnaire as the main instrument, while the qualitative study used interview method.

The first process was the survey. The survey can reveal the information of respondents about the subject being studied; things are done 
at an earlier time, and the next thing about the behavior of the respondent or others (Kerlinger, 2002). Survey involves multiple steps or levels or selection with stratification and grouping units into various groupings, as well as survey research aims to describe a method of gathering information from samples of the larger population (Ferber et.al., 1980). The procedures are: 1) Design questions; 2) Collecting data and Instrumentation; 3 ) analysis of the data.

The second was interview. According to Lincoln and Guba (1985) that the interview be declared as a conversation that seeks to obtain construction was happening now about people, events, activities, organizations, feelings, motivation, recognition, anxiety and so on. The procedures are: 1) providing several questions related to assessment for learning using constructive alignment; 2) collecting data by doing interviews; 3 ) interpreting the interviews result and; 4) analysis the data.

\section{FINDING AND DISCUSSION}

The study conducted at four universities in Indonesia, from February until May 2014. The number of respondents who participated to the survey was 454 lecturers with 197 (43.4) of them were males and 257 (56.6) females.

The table shows data about demographic background of assessment for learning and constructive alignment, with a further classification by level of gender, age, teaching experiences, academic qualifications, and department. A steady but significant increase can be seen in the percentage of the respondents, which possessed gender (female). It was in line with competition increases to academic qualification and and department as well as the number of respondents' teaching experience and their age. Whereas by 265 (58.4 percent) out of 454 respondents belonged to master of academic qualification.

An analysis of the data by level of education shows 257 (56.6 percent) out of 454 respondents belonged to department of education. In teaching experience, only 1 ( 0.2 percents) out of 454 respondents came from the others. The lecturers who were teach between 6-10 years were considerable majority, of approximately 30.20 percentage. While the majority respondents 143 (31.5 percent) who aged between $36-40$ years old. Assessment for learning (AFL) mean values for female (4.53) was higher than male (3.91). The analysis of t-test showed that the difference was significant at the 0.05 level. Findings show the data of gender (Male and Female), with a further classification by values of mean, standard deviation, and standard error of assessment for learning. An analysis of the data by values indicates positive response to the practice of AfL by looked at the gender difference. Total mean score of gender is 4.25 and standard deviation is 0.384 showed that they were higher than $\alpha 0.05$.

Constructive Alignment (CA) mean value of female (4.49) was higher than male (3.86). The analysis of Anova showed that the difference was significant at the 0.05 level. The findings show the data of gender, with a further classification of values of mean, standard deviation, and standard error of constructive alignment. An analysis of the data by values indicates a positive response to the practice of CA by looking at the gender difference. The total mean score of gender is 4.21 and the standard deviation is 0.43 showed that they were higher than $\alpha 0.05$.

Assessment for Learning (AFL) mean values in terms of age showed the highest mean (4.60) for the $61-65$ year age group followed by (4.43) for the 46 - 50 year age group, (4.41) $41-$ 45 , (4.40) $51-55,(4.35) 56-60,(4.20) 36-40$, (4.10) $25-30$, and (4.04) 31 - 35 year age group. There was a positive and significant correlation between age and AFL, where $\mathrm{r}=0.325, \mathrm{p}<$ 0.000 , the relationship was weak. The pattern also showed that the higher in the age of the AfL values. Constructive Alignment (CA ) mean values in terms of age showed the highest mean (4.41) for the $61-65$ year age group followed by (4.40) for the 46 - 50 year age group, (4.34) $41-$ 45 , (4.33) $51-55$, , (4.23) $56-60$, , (4.20) $36-40$, (4.02) $25-30$, and (4.00) 31 - 35 year age group.

\section{REFERENCES}

Assessment Reform Group. (2002). Assessment for learning: Research-based principles of assessment for learning to guide classroom practice. Retrieved from http://www. assessment-reform-group.org.uk

Biggs, J. (1996). Enhancing teaching through constructive alignment. Higher Education. Vol. 32, pp. 1-18. 
Demography Background of AfL and CA

\begin{tabular}{|c|c|c|c|c|c|}
\hline & & \multirow{2}{*}{$\mathbf{N}$} & \multirow{2}{*}{$\begin{array}{c}\text { Sample Percent- } \\
\text { age }\end{array}$} & \multicolumn{2}{|c|}{ Mean Value } \\
\hline & & & & $\mathbf{C A}$ & AfL \\
\hline \multirow{2}{*}{ Gender } & Male & 197 & 43.4 & 3.86 & 3.91 \\
\hline & Female & 257 & 56.6 & 4.49 & 4.53 \\
\hline \multirow{8}{*}{ Age } & $25-30$ & 30 & 6.6 & 4.02 & 4.10 \\
\hline & $31-35$ & 71 & 15.6 & 4.00 & 4.04 \\
\hline & $36-40$ & 143 & 31.5 & 4.20 & 4.20 \\
\hline & $41-45$ & 58 & 12.8 & 4.34 & 4.41 \\
\hline & $46-50$ & 57 & 12.6 & 4.40 & 4.43 \\
\hline & $51-55$ & 64 & 14.1 & 4.33 & 4.40 \\
\hline & $56-60$ & 24 & 5.3 & 4.23 & 4.35 \\
\hline & $61-65$ & 7 & 1.5 & 4.41 & 4.60 \\
\hline \multirow{8}{*}{ Experience } & $1-5$ & 97 & 21.4 & 4.00 & 4.03 \\
\hline & $6-10$ & 137 & 30.2 & 4.20 & 4.20 \\
\hline & $11-15$ & 78 & 17.2 & 4.40 & 4.36 \\
\hline & $16-20$ & 68 & 15.0 & 4.41 & 4.43 \\
\hline & $21-25$ & 41 & 9.0 & 4.40 & 4.45 \\
\hline & $26-30$ & 24 & 5.3 & 4.11 & 4.27 \\
\hline & $31-35$ & 8 & 1.8 & 4.20 & 4.41 \\
\hline & $36-40$ & 1 & .2 & 5.00 & 4.87 \\
\hline \multirow[t]{2}{*}{ Qualification } & Master & 265 & 58.4 & 4.10 & 4.15 \\
\hline & Doctorate & 189 & 41.6 & 4.40 & 4.40 \\
\hline \multirow{5}{*}{ Department } & Social & 3 & .7 & 2.75 & 3.13 \\
\hline & Psychology & 22 & 4.8 & 3.30 & 3.54 \\
\hline & Science & 135 & 29.7 & 3.84 & 3.96 \\
\hline & Education & 257 & 56.6 & 4.42 & 4.42 \\
\hline & Language & 37 & 8.1 & 4.86 & 4.80 \\
\hline
\end{tabular}

Biggs, J. (1999). What the student sdoes: teaching for enhanced learning. Higher education \& Development. Vol. 18, No. 1,pp. 57-75. http:// dx.doi.org/10.1080/0729436990180105

Biggs, J. \& Tang, C. (2007). Teaching for Quality Learning at University (The society for research in higher education). Third Edition. New York, USA: Open University Press.

Berry, R., \& Adamson, B. (Eds.). (2011). Assessment reform in education: Policy and practice. New York: Springer.

Berry, R. (2008). Assessment for Learning. Hong Kong Teacher Education. Hong Kong: Hong Kong University Press.

Boud, D., \& Falchikov, N. (2006). Aligning assessment with long-term learning. Assessment \& Evaluation in Higher
Education, Vol. 31, No. 4, pp. 399-413.http:// dx.doi.org/10.1080/02602930600679050

Carless, D. (2007a). Learning-oriented assessment: Conceptual basis and practical implications. Innovations in Education and Teaching International, 44(1), 57-66.

Creswell, J.W. (2009). Research Design: Qualitative, Quantitative and Mixed Methods Approaches. Third Edition. Thousand Oaks, Califiornia: Sage Publication, Inc.

Creswell, J.W. (2012). Educational Research (Planning, Conducting and Evaluating Quantitative and Qualitative Research). Fourth Edition. Boston, USA: Pearson.

Hogan, D., \& Gopinathan, S. (2008). Knowledge management, sustainable innovation, and pre-service teacher education in Singapore. 
Teachers and Teaching: Theory and Practice. Vol. 14, No. 4, pp. $369-384$.

Johnson, R. B., \& Onwuegbuzie, A. J. (2004). Mixed methods research: A research paradigm whose time has come. Educational Researcher, 33, 14-26.

Klenowski, V. (2009). Assessment for Learning revisited: an Asia-Pasific perspective. Assessment in Education: Principle, Policy \& Practice. Vol. 16, No. 3, pp. $263-268$.

Mok, M.M.C., (Eds.). (2012). Assessment Reform in the Asia-Pacific Region: The theory and practice of self-directed learning oriented assessment. New York: Springer.
Sadler, D. R. (1998). Formative assessment: Revisiting the territory. Assessment in Education: Principles, Policy, and Practice, 5, 77-84.

Sambell K, McDowell L,. \& Montgomery, C. (2013). Assessment for Learning in Higher Education. London and New York: Routledge.

Scriven, M. (1967) The methodology of evaluation (Washington, DC, American Educational Research Association). 